\title{
Macroanatomical comparison and examination of external carotid artery and last branches in the Abaza (Capra aegagrus) and Gurcu (Capra falconeri) goats
}

\section{Research Article}

Volume: 5, Issue: 3

December 2021

Pages: $130-135$

\section{Article History}

Received: 25.07.2021

Accepted: 23.10.2021

Available online:

27.10.2021

\section{Semine DALGA ${ }^{1}$, Kadir ASLAN ${ }^{1}$}

1. Department of Anatomy, Faculty of Veterinary Medicine, Kafkas University, Kars, Turkey. Dalga S. ORCID: 0000-0001-7227-2513, ASLAN K. ORCID: 0000-0002-7617-0175

\begin{abstract}
The aim of this research is to macroanatomically compare and examine the arteria carotis externa and its last branches that provide arterial vascularization of the head region of Abaza and Gurcu goats. For this purpose, a total of 10 Abaza and 10 Gurcu goat heads were used. In both goat breeds, a. carotis communis continued as a. carotis externa. In both goat breeds, according to the vessel order not taking place in Nomina Veterinaria Anatomica, a common root belonging to a. temporalis superficialis and a. transversa faciei was observed. In addition to this common root, the presence of a common stem belonging to a. malaris and a. infraorbitalis, not mentioned in the nomina, in both goat breeds was detected. In Gurcu goats, a. lingualis dextra disappeared by getting thinner after being seperated from a. carotis externa in $70 \%$ of the materials. As a result, although the distribution of a. carotis externa in the head region of Abaza and Gurcu goats is generally similar to other small ruminants, some differences were determined in the origin points, courses and the number of sub-branches of the branches originating from the a. carotis externa.
\end{abstract}

Keywords: Abaza goat, A. carotis externa, Gurcu goat

This study has been summarized from Semine DALGA Phd thesis.

DOI: https://doi.org/10.30704/http-www-jivs-net.974302

To cite this article: Dalga, S., Aslan, K., (2021). Macroanatomical comparison and examination of external carotid artery and last branches in the Abaza (Capra aegagrus) and Gurcu (Capra falconeri) goats. Journal of Istanbul Veterinary Sciences, 5(3), 130-135. Abbreviated Title: J. İstanbul vet. sci.

\section{Introduction}

Abaza goat (Capra aegagrus): Abaza goats, which are mainly bred in the province of Artvin in Turkey, are generally bronze, white, black and brown in color (figure 1). The mouth, around the eyes, horns and legs may be black. It is in thin form in terms of body structure and therefore, it is likened to gazelle. The females can be horned or hornless, while the males have xiphoid, flat and broadly shaped horns. The horn structure of the females with horns is small and similar to that of a male goat (Batu 1951, Sezgin et al 2010).

Gurcu goat (Capra falconeri): Gurcu goats, also known as Tbilisi goat or Caucasian goat, whose origins are Caucasian, are bred and raised in Northern Anatolia, especially in the province of Kars and Çıldır a district of Ardahan. The Gurcu goat, which is mostly in black, gray

*Corresponding Author: Semine Dalga

E-mail: semine_1980@hotmail.com

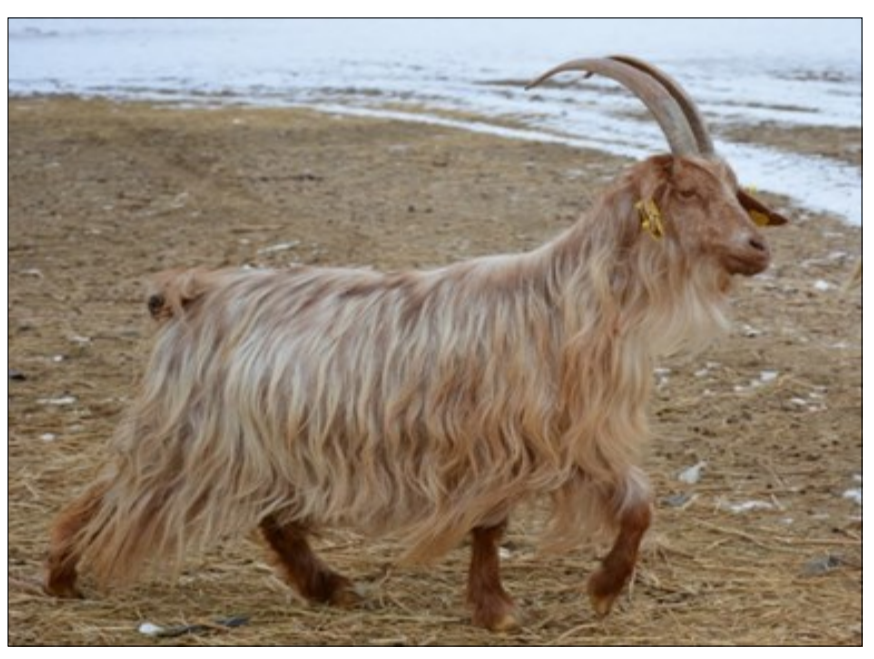

Figure 1. Abaza goat

Journal home page: www.jivs.net http://dergipark.gov.tr/http-www-jivs-net 
and white colours, originates from the auger horned goat Capra falconeri (Batu 1951, Sezgin et al 2010, Yalçın et al 1990). The horn structure of the male goats differs from the hair goats. The long and upright horns of male Gurcu goats touch each other at the tip (Figure 2). Gurcu goats' horns are sometimes seen to reach $50 \mathrm{~cm}$ (Batu 1951).

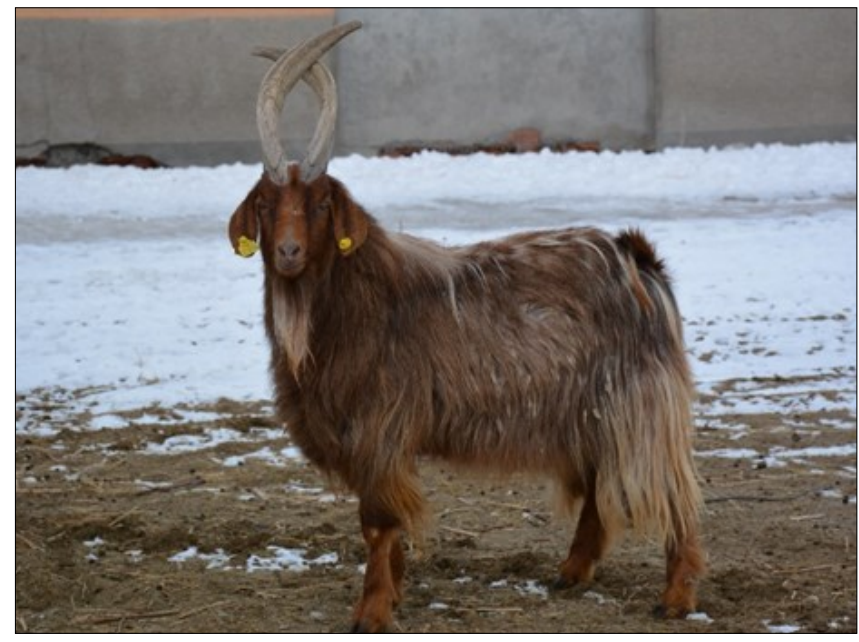

Figure 2. Gurcu goat

Considering the importance of the anatomy and circulatory system, the circulatory system is a system in which many variations of the artery and vascular system can be seen (Dursun, 2000). There are several methods that solidify into the vessel and allow us to examine the course of the vessels and their subbranches in order to successfully examine and understand this highly complex system. There studies examining the circulatory system in ruminantia using these methods in the literature, (Akbulut and Aslan 2013, Beki 2017).

The aim of this research is to macroanatomically compare and examine the a. carotis externa and its last branches that provide arterial vascularization of the head region of Abaza and Gurcu goats.

\section{Materials and Methods}

Abaza and Gurcu skulls were used in this study. First of all, permission was obtained from the Kafkas University Animal Experiments Local Ethics Committee (KAÜ-HADYEK/2018-003). After receiving the approval a total of 10 Abaza and Gurcu goat heads were provided from the education, research and application farm, regardless of gender. The arteries of the materials were washed with a $0.9 \%$ saltwater solution (Erençin et al 1967). Then, the arteries were filled with latex (300-400 cc. latex and $25 \mathrm{cc}$. artdeco fabric dye) colored with red dye (Aycan and Bilge 1984, Beşoluk et al 2006, Bugge 1963). After the latex solidified, the skin on the skulls was removed. The arteria carotis externa and its branches running ventral to the glandula parotid were dissected along their course and findings were obtained.

\section{Results}

At the level of processus transversus of the atlas, the arteria carotis externa (a.) is seen to be separated from common carotid artery (Figure 3-4/1). In both goat breeds, it was observed that the common root belonging to a. auricularis caudalis, a. temporalis superficialis and a. transversa faciei and a. lingualis originated from the a. carotis externa.

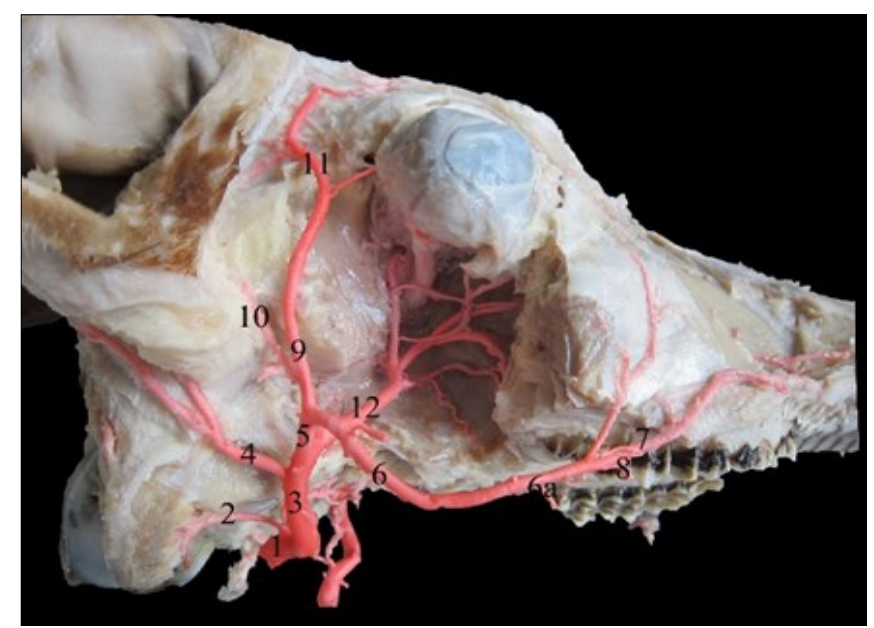

Figure 3. Arteria carotis communis and its branches in the Abaza goat. 1. a. carotis communis, 2. a. occipitalis, 3. a. carotis externa, 4 . a. auricularis caudalis, 5 . a common stem belonging to a. temporalis superficialis and a. transversa faciei, 6. a. transversa faciei, 6a. r. masssetericus, 7. a. labialis superior, 8. a. labialis inferior, 9. a. temporalis superficialis, 10. a. auricularis rostralis, 11. a. cornualis, 12. a. maxillaris.

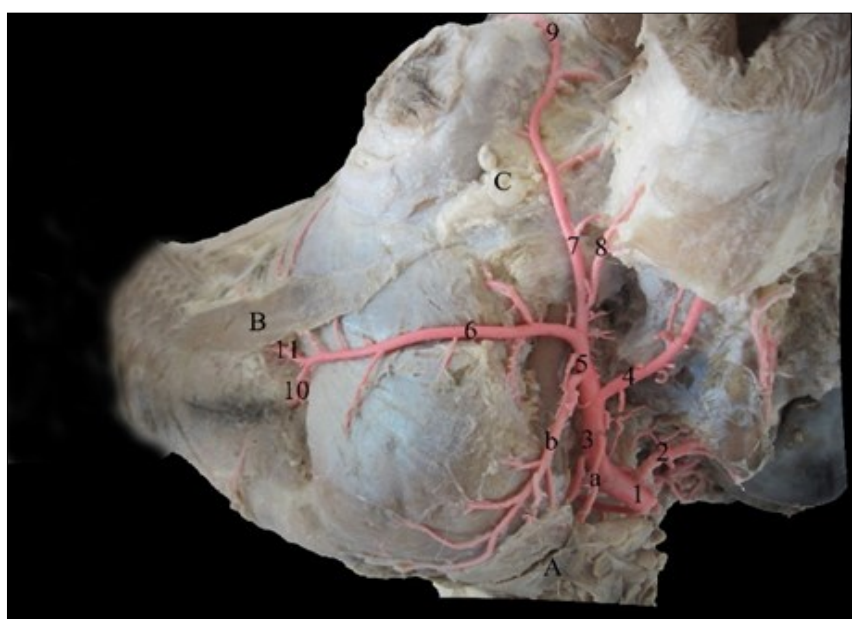

Figure 4. Arteria carotis communis and its branches in the Gurcu goat. 1. a. carotis communis, 2. a. occipitalis, 3. a. carotis externa, 4. a. auricularis caudalis, 5. a common stem belonging to a. temporalis superficialis and a. transversa faciei, 6. a. transversa faciei, 7. a. temporalis superficialis, 8. a. auricularis rostralis, 9. a. cornualis, 10. a. labialis inferior, 11. a. labialis superior, a. ramus glandularis, b. branch from the artery carotis externa to the ventral edge of the mandible, A: Gl. mandibularis, B: $M$. zygomaticus, C: Corpus adiposum. 
In both goat breeds, it was determined that the rr. glandularis, which goes to gl. parotis, is originated from the stem belonging to a. temporalis superficialis and a. transversa faciei that separates from a. carotis externa as a common stem (Figure 3-4). Furthermore, a strong branch originating from the common stem in Gurcu goats was found to move towards the ventral edge of the mandible (Figure 4/5). In both goat breeds, it was seen that the a. auricularis caudalis provided the arterial vascularization of the ear by dividing into last two branches after giving branches primarily going to gl. Parotis (Figure 3-4/4).

In the Abaza and Gurcu goats, it was seen that a. temporalis superficialis gave a. auricularis rostralis after the origin, then gave the common stem belonging to a. palpebralis superior lateralis and $a$. palpebralis inferior lateralis towards the orbita, ramus lacrimalis and a. cornualis going towards gl. lacrimalis and ended by spreading in the frontal region. In $30 \%$ of the Abaza goats, it was seen that the a. auricularis rostralis was seperated from the common stem of a. temporalis superficialis and a. transversa faciei.

In both breeds, it was observed that the a. transversa faciei provided $\mathrm{m}$. masseter's arterial vascularization, and it divided into two branches as a. labialis superior and a. labialis inferior at the front edge of the $\mathrm{m}$. masseter (Figure 4/10-11).

In the Abaza and Gurcu goats, it was observed that the a. lingualis was separated from the lateral face of a. carotis externa. In $70 \%$ of the materials in Gurcu goats, a. lingualis dextra was observed to be disappeared after being separated from a. carotis externa and the right side of the tongue was fed by a strong branch coming from a. lingualis sinistra (Figure $5 / 1)$. In both goat breeds, it was determined that the a. profunda lingua, which is the continuation of a. lingualis, anastomosed with a similar vessel in the opposite side of the apex of the tongue (Figure5-6).

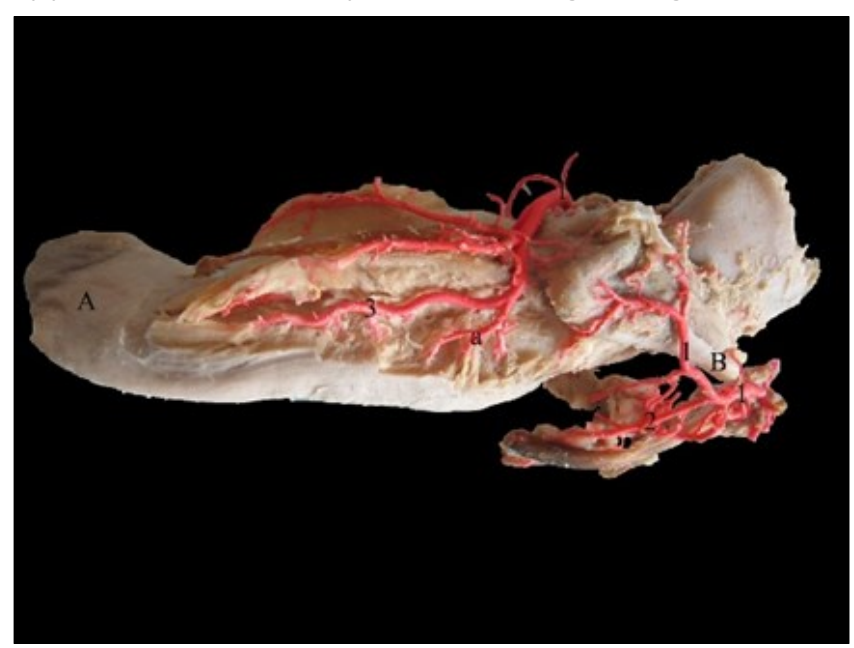

Figure 5. A. lingualis and branches in Gurcu goat. 1. a. lingualis, 2. rr perihyoidei, 3. a. profunda linguae, a. rami dorsales linguae, A: Apex linguae, B: Os hyoideum.

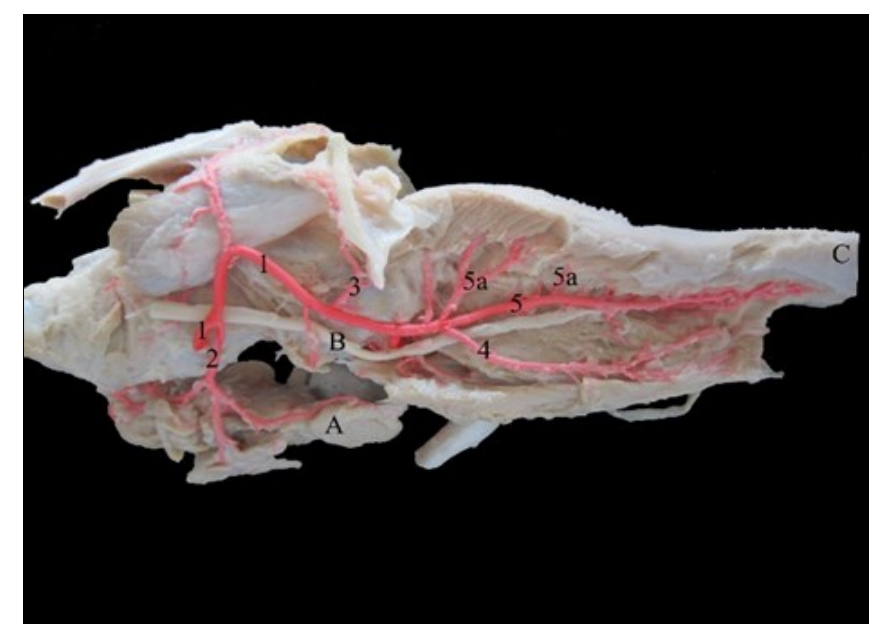

Figure 6. A. lingualis and branches in Abaza goat. 1. a. lingualis, 2. Ramus glandularis, 3. rr. perihyoidei, 4. a. sublingualis, 5. a. profunda linguae, 5a. Rami dorsales linguae, A: Glandula mandibularis, B: Nervus lingualis, C: Apex linguae.

In both goat breeds, it was also observed that the a. maxillaris, which is the continuation of a. carotis externa, ended by giving a common stem for a. alveolaris inferior, a. buccalis, a. temporalis profunda, a. ophthalmica externa, a. malaris and a. infraorbitalis, respectively, and finally for a. sphenopalatina and a. palatina descendens (Figure 7-8).

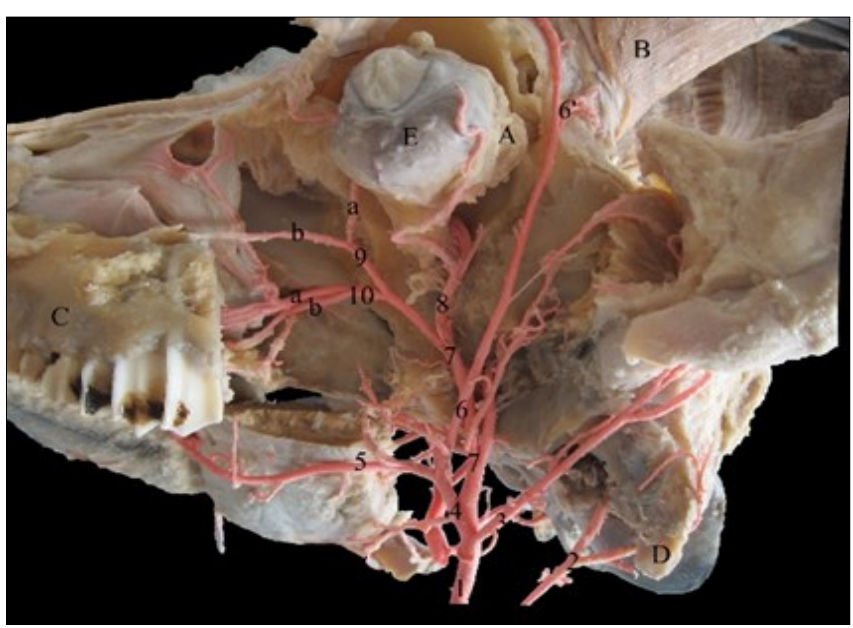

Figure 7. Arteria maxillaris and terminal branches in Gurcu goats. 1. a. carotis communis, 2. a. occipitalis, 3. a. auricularis caudalis, 4. common root of arteria temporalis superficialis and arteria transversa faciei, 5. a. transversa faciei, 6. a. temporalis superficialis, 6. a. cornualis, 7. a. maxillaris, 8. a. ophthalmica externa, 9. common root of arteria malaris with arteria infraorbitalis, a. a. malaris, b. a. infraorbitalis, 10 . common root of arteria sphenopalatina with arteria palatina descendens, a. a. palatina descendens, b. a. palatina minör, A: Gl. lacrimalis, B: Proc. cornualis, C: Os maxilla, D: Condylus occipitalis, E: Bulbus oculi.

In the Abaza and Gurcu goats, it was observed that the a. alveolaris inferior was originated from a. maxillaris, and ended as a. mentalis after coming out from for. mentale by following a straight course within the canalis mandibularis. 
In both goat breeds, it was seen that the a. ophthalmica externa was separated from a. maxillaris as a single stem (Figure $7 / 8$, Figure $8 / 10$ ). It was ovserved that the vessel formed a. lacrimalis first and then rete mirabile ophthalmicum after giving various branches to the eye muscles. Then, it gave a. ethmoidalis externa and a. supraorbitalis with two branches. In both goat breeds, it was observed that a common stem belonging to a. malaris and a. infraorbitalis is separated from a. maxillaris, a. malaris moves towards the medial angle of the eye and feeds this area, and the a. infraorbitalis is ended on the sides of the nose by passing through the canalis infraorbitalis (Figure 9). In the Abaza and Gurcu goats, it was determined that the a. palatina descendens and a. sphenopalatina were separated from a. maxillaris with a common stem, the palatina descendens feeds the nasal cavity, and the a. sphenopalatina was divided into two branches as a. palatina major and a. palatina minor (Figure 7-8).

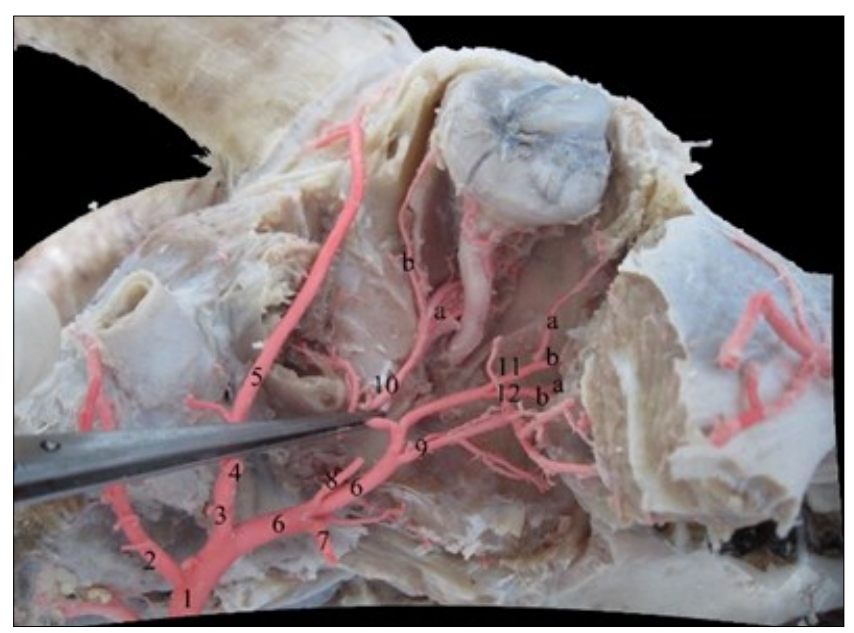

Figure 8. Arteria maxillaris and terminal branches in Abaza goats. 1. a. carotis externa, 2. a. auricularis caudalis, 3. common root of arteria temporalis superficialis and arteria transversa faciei, 4. a. transversa faciei, 5. a.temporalis superficialis, 6. a. maxillaris, 7. a. alveolaris inferior, 8. $r$. caudalis ad rete mirabile epidurale rostrale, 9. a. buccalis, 10. a. ophthalmica externa, a. rete mirabile ophthalmicus, b. ramus lacrimalis, 11 . common root of arteria malaris with arteria infraorbitalis, a. a. malaris, b. a. infraorbitalis, 12. common root of arteria sphenopalatina with arteria palatina descendens, a. a. sphenopalatina, b. a. palatina descendens

\section{Discussion}

Researches stated that (Dursun 2000, Doğuer and Erençin 1966, Najafi et al 2008, Ghoshal 1975, Dalga and Aslan 2016), a. carotis externa is a continuation of a. carotis communis in terms of its course and thickness. In our study, in both Abaza and Gurcu goats, the a. carotis externa was determined to be the continuation of a. carotis communis.

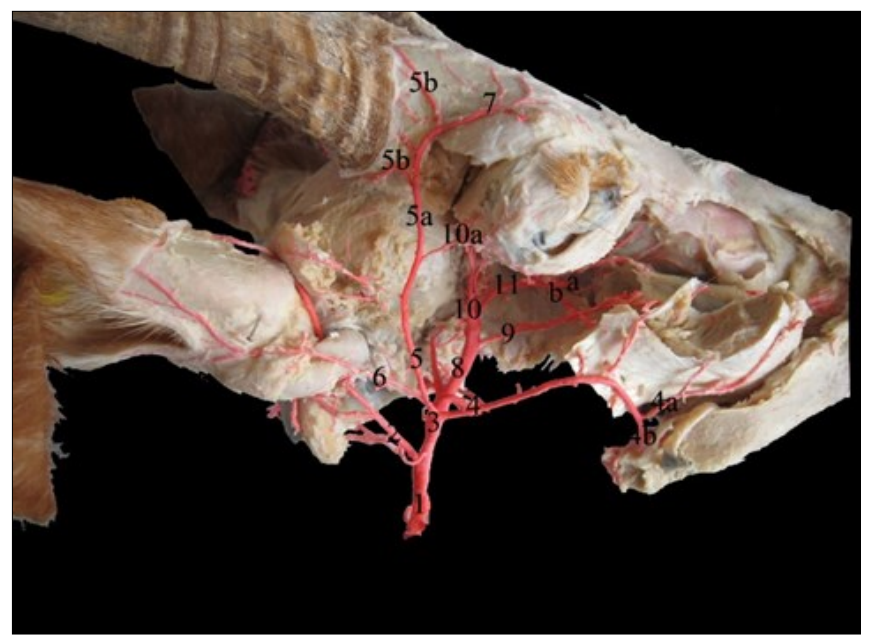

Figure 9. Arteria maxillaris and terminal branches in Abaza goats. 1 . a. carotis externa, 2. a. auricularis caudalis, 3. common root of arteria temporalis superficialis and arteria transversa faciei, 4. a. transversa faciei, 4a. a. labialis superior, 4b. a. labialis inferior, 5 . a. temporalis superficialis, 5 a. branch of the arteria temporalis superfialis scattering to the regio temporalis, 5b. a. cornualis, 6. a. auricularis rostralis, 7. A. dorsalis nasi, 8. a. maxillaris, 9. a. buccalis, 10. a. ophthalmicus externa, 10a. rr. musculares, 11. common root of arteria malaris with arteria infraorbitalis, a. a. malaris, b. a. infraorbitalis.

Dalga and Aslan (2016) reported that the a. lingualis originates from the lateral face of a. carotis externa in the Hemşin sheep, while Nur and Dursun (1992a) reported that the a. lingualis originates from the front face of the a. carotis externa in the Akkaraman sheep. Beki (2017) examined the Tuj sheep and reported that a. lingualis originates from the front face of a. carotis externa. Furthermore, in the Abaza and Gurcu goats, it was determined that the a. lingualis originates from the front face of the a. carotis externa, and participated in arterial nutrition of gl. mandibularis, m. masseter, m. hyoglossus and $\mathrm{m}$. genioglossus. Then, it was divided into the last end branches called a. sublingualis and a. profunda linguae. Nur and Dursun (1992a, 1992b), it was reported that the rr. dorsales lingules ranging from 6 to 8 in number originates from a. profunda linguae for the dorsum linguae in Akkaraman sheep and Angora goat. Dalga and Aslan (2016), reported that the a. profunda linguae follows a spiral course. Baki (2017), examined the Tuj sheep and reported that the a. profunda linguae, which is the continuation of a. lingualis, advances in a straight line and gives the rr. dorsales linguales, whose number varies between 1012 , for the dorsum linguae. In the Abaza and Gurcu goats, it was determined that a. lingualis and its continuation a. profunda linguae follow a straight course and gives a smaller number of rami dorsales linguales for the dorsum linguae. As stated in the findings, a finding that is not included in the literature 
review was obtained for Gurcu goats. In $70 \%$ of the materials in Gurcu goats, a. lingualis dextra was observed to be disappeared after being originated from a. carotis externa and the right side of the tongue was fed by a strong branch coming from a. lingualis sinistra.

According to the studies conducted on the Akkaraman sheep, Angora goat, (Nur and Dursun 1992a, 1992b), Hemşin sheep (Dalga and Aslan 2016) and Tuj sheep (Beki 2017), a. temporalis superficialis and a. transversa faciei originate from the a. carotis externa as a common root. It has been reported that the a. temporalis superficialis and a. transversa faciei in buffalo (Özdemir and Tıpırdamaz 2002) and Zavot breed cattle (Akbulut ve Aslan 2013) originates at different levels from the a. carotis externa. In this study conducted on the Abaza and Gurcu goats, the results were found to be consistent with the results of the studies conducted on the Hemşin and Akkaraman sheep, and it was determined that a. temporalis superficialis and a. transversa faciei are separated from a. carotis externa as a common root. However, this common root was not seen in the terms included in Nomina Anatomica Veterinaria (2017). In addition, in our study, it was determined that the common root length was longer in Gurcu goats compared to Abaza goats. Dalga and Aslan (2016), it was stated that the a. auricularis rostralis originates from the common root of a. temporalis superficialis and a. transversa faciei in the Hemşin sheep. It was also determined that the a. auricularis rostralis originates from a. temporalis superficialis and a. transversa faciei at a rate of $80 \%$ in the Akkaraman sheep (Nur and Dursun 1992b) and originates from a. temporalis superficialis in the Angora goat (Nur and Dursun 1992a). On the other hand, it was reported that the a. auricularis rostralis originates from the caudal face of a. temporalis superficialis in the Tuj sheep (Beki 2017). In our study, it was determined that the a. auricularis rostralis was separated from the common root of a. temporalis superficialis and a. transversa faciei in \%30 of the Abaza goats, which is similar to the arterial structure in the Hemşin and Akkaraman sheep. This situation in Gurcu goats was determined to be consistent with the Tuj sheep and Angora goat. Nur and Dursun (1992a, 1992b), reported that the a. palpebralis superior lateralis and a. palpebralis inferior lateralis are separated from a common root originated from a. temporalis superficialis in $45 \%$ of the the Angora goats and $30 \%$ of the Akkaraman sheep. In our study, it was observed that the a. palpebralis superior lateralis and a. palpebralis inferior lateralis are separated from a common root originated from a. temporalis superficialis in both goat breeds. In our study, the finding stating that the a. temporalis superficialis is weaker than a. transversa faciei is consistent with the literature (Beki 2017, Doğuer and Erençin 1966, Bilgiç 1987).

Ghoshal (1975) and Dursun (2000) reported that the a. maxillaris, which is one of the end branches of a. carotis externa, is the continuation of a. carotis externa with its thickness. In addition, the a. maxillaris was observed to be the continuation of a. carotis externa in the Abaza and Gurcu goats. The fact that the a. maxillaris gave the a. ophthalmica externa after giving the a. alveolaris inferior and a. buccalis, formed the rete mirabile ophthalmicum between $\mathrm{m}$. rectus dorsalis and $\mathrm{m}$. retractor bulbi at the level of for. orbitorotundum showed that it is consistent with the information presented in the literature (Dursun 2000).

Akbulut and Aslan (2013) reported that the a. alveolaris inferior originates from a. maxillaris, and follows a spiral course within the canalis mandibularis after entering the mandible foramen, and continued to the mental formen in Zavot breed cattle. As a matter of fact, Dalga and Aslan (2016) reported that the a. alveolaris inferior follows a straight course in the Hemşin sheep. Furthermore, Beki (2017) reported that the a. alveolaris inferior follows a straight course in the Tuj sheep. It was observed that the a. alveolaris inferior follows a straight course within the canalis mandibularis in both Abaza and Gurcu goats similar to Hemşin and Tuj sheep. Özdemir and Tıpırdamaz (2002) reported that the a. ophthalmica externa originates from a. maxillaris as two roots, while Diesem (1975), Ghoshal (1975) and Schummer et al (1981) reported that the a. ophthalmica externa is separated from a. maxillaris as a single root in the Tuj sheep Beki and Akbulut (2017). It was observed that the a. ophthalmica externa is separated from a. maxillaris as a single root in both Abaza and Gurcu goats. In our study, as stated in the literature Dursun (2000), Ghoshal (1975), the a. lacrimalis, which is originated from rete mirabile ophthalmicum, follows a course towards gl. lacrimalis and ends in gl. lacrimalis.

Dursun (2000) reported that the a. malaris originates from a. maxillaris, Dalga and Aslan (2016) reported that the mentioned vessel originates from a. infraorbitalis. Beki (2017) stated that the a. malaris originates from a. maxillaris with a. infraorbitalis as a single root in the Tuj sheep. In the Abaza and Gurcu goats, this situation is consistent with the Tuj sheep. In both goat breeds, it was observed that a. malaris is separated from a. maxillaris with a. infraorbitalis as a single root. In the terms included in Nomina Anatomica Veterinaria (2017), it was stated that the a. malaris and a. infraorbitalis are separately originated from a. maxillaris. Despite the literature information reporting that there is an anastomosis between the a. malaris and a. maxillaris in sheep, no such finding was encountered in our study. 
As a result, in the Abaza and Gurcu goats, although the distribution of a. carotis externa in the head region of Abaza and Gurcu goats is generally similar to other small ruminants, some differences were determined in the origin points, courses and the number of sub-branches of the branches originating from a. carotis externa. Accordingly;

In $70 \%$ of the materials in Gurcu goats, a. lingualis dextra was observed to be disappeared after being originated from a. carotis externa and the right side of the tongue was fed by a strong branch coming from a. lingualis sinistra. In Nomina Anatomica Veterinaria (2017), it was stated that the a. transversa faciei and a. temporalis superficialis are separately branched from a. carotis externa. However, in our study, these vessels in both goat breeds were determined to be branched from a common root separated from dorsal face of the a. carotis extern. Despite the fact that Nomina Anatomica Veterinaria (2017) stated that the r. sternocleido mastoideus are separated from a. auricilaris profunda, it was not found in either goat breed. In the Abaza goats, it was seen that $30 \%$ of the materials of a. auricularis rostralis was seperated from the common root of a. temporalis superficialis and a. transversa faciei. Unlike the vessel names specified for the goats in Nomina Anatomica Veterinaria (2017), it was determined that the a. malaris and a. infraorbitalis were seperated from a. maxillaris as a common root in both goat breeds. It is thought that our study will compensate the deficiency on this subject relatively and will be a reference in determining the head region vascular differences between species in future studies.

\section{Acknowledgement}

This study, supported by the Scientific Research Projects Directorate of KAFKAS University (KAÜ/BAP) as the project numbered "2018-TS-49".

\section{References}

Akbulut, Y., \& Aslan, K. (2013). In Zavot breed cattle a. macroanatomical studies on the carotis externa and its last branches. Atatürk University Journal of Veterinary Sciences, 8(1), 63-70.

Aycan, K., \& Bilge, A. (1984). Investigation of the anatomy of the vascular system with plastic injection and corrosion method. Erciyes Medical Journal 6(4), 545-552.

Batu, S. (1951). Turkey goat breeds. Ankara, Turkey: Ankara University Faculty of Veterinary Medicine Publications.

Beki, B., \& Akbulut, Y. (2017). Macroanatomical studies on arteria carotis externa and its last branches in Tuj sheep. Master's thesis, University of Kafkas, Kars, Turkey.

Besoluk, K., Eken, E., \& Bahar, S. (2006). The branches of the descending palatine artery and their relation to the vomeronasal organ in Angora goats. Veterinary Medicina, 51(2), 55-59.
Bilgiç, S. (1987). Macroanatomical studies on arteria carotis communis and its last branches in Akkaraman sheep and Hair goat. Phd Thesis, University of Firat, Institute of Health Sciences, Elazığ, Turkey.

Bugge, J. (1963). A standardised plastic injection technique for anatomical pusposes. Acta Anatomica, 51, 177-192.

Dalga, S., \& Aslan, K. (2016). Macroanatomical research on arteria carotis externa and its last branches in Hemsin Sheep. Atatürk University Journal of Veterinary Sciences, 11(2), 178-184.

Diesem, C. (1975). Ruminant sense organs and common integument in "The Anatomy of the Domestic Animals", Ed By R. Getty. Philadelphia, US: WB. Saunders.

Doğuer, S., \& Erençin, Z. (1966). Comparative angiography of pets. Ankara, Turkey: Ankara University Printing house.

Dursun, N. (2000). Veterinary Anatomy II. Ankara, Turkey: Medisan publishing.

Erençin, Z., Hassa, O., Sağlam, M., \& Evren, A. (1967). Development of plastic demonstration methods for injection vein and canal systems. Atatürk University Journal of Veterinary Sciences, 14(3), 444-452.

Ghoshal, N. G. (1975). Ruminant heart and arteries in he anatomy of the domestic animals. Ed. By R. Getty, 9601024, Philadelphia, US: WB, Saunders.

Najafi, G., Ahmedi, A., \& Razi, M. (2008). The topographical anatomy, Blood and nerve supply of the carotid body in the cattle (1-3 years old). Journal of Animals and Veterinary Advences, 7(6), 673-675.

Nomina Anatomica Veterinaria (2017). International Committee on Veterinary Gross Anatomical Nomenclature, General Assembly of the World Association of Veterinary Anatomists. 6th edition, Gent. Belgium.

Nur, i. H., \& Dursun, N. (1992a). Comparative macroanatomical and subgross studies on the last branches of the arteria carotis communis in Akkaraman sheep and Angora goat. Phd Thesis, University of Selçuk, Institute of Health Sciences, Konya, Turkey.

Nur, i. H., \& Dursun, N. (1992b). Macroanatomical and subross studies on arteria carotis externa and branches in Angora goats. Van Veterinary Journal, 3 (1-2), 209-226.

Özdemir, V., \& Tıpırdamaz, S. (2002). Macroanatomical research on arteria carotis communis and end branches in buffaloes. Phd Thesis, University of Selçuk, Institute of Health Sciences, Konya, Turkey.

Schummer, A., Wilkens, H., Vollmershaus, B., Habermehl, K. H., (1981). The circulatory system, the skin and the cutaneus organs of the domestic mammals. Vol 3, Ed By Nickel R, Schummer A, Seiferle E, Verlag Paul Parey, Berlin- Hamburg.

Sezgin, E., Kopuzlu, S., \& Yüksel, S. (2010). Abaza goats. National Goat Breeding Congress, Çanakkale; pp. 241244.

Yalçın, B. C., Aytuğ, C. N., Alaçam, E., Özkoç, Ü., Gökçen, H. Et al., (1990). Sheep-Goat Diseases and Breeding. TÜM VET Animal Services Broadcast, Teknografik Press, Istanbul, Turkey. 